\title{
РАЗРАБОТКА КОНЦЕПТУАЛЬНОЙ МОДЕЛИ УПРАВЛЕНИЯ ЭКОЛОГИЧЕСКИМИ ИННОВАЦИОННЫМИ ПРОЕКТАМИ В ОРГАНИЗАЦИИ
}

\section{(C) 2021 Лямин Борис Михайлович}

кандидат экономических наук, старший преподаватель Высшей школы сервиса и торговли Санкт-Петербургский политехнический университет Петра Великого, Россия, Санкт-Петербург

E-mail: Lyamin.bm@gmail.com

\section{(c) 2021 Черникова Анна Владимировна}

кандидат экономических наук, доцент Высшей школы сервиса и торговли

Санкт-Петербургский политехнический университет Петра Великого, Россия, Санкт-Петербург

В статье представлен глубокий анализ трудов отечественных и зарубежных ученых в области управления экологическими инновационными проектами, на основании которого разработана концептуальная модель управления экологическими инновационными проектами в условиях цифровой трансформации. Модель позволяет формализовать последовательность действий для субъектов управления организацией, чтобы выбрать наиболее результативные проекты, которые способствуют достижению стратегических целей предприятия, с учетом внешних и внутренних факторов.

Ключевые слова: экологические инновационные проекты, концептуальная модель, анализ подходов к управлению экологическими проектами

На современном этапе развития экономики организациям для достижения устойчивого развития необходимо системно совершенствовать все сферы деятельности. Особенно важным аспектом является повышение эффективности производственной деятельности: появляются новые технологии, материалы, методики, позволяющие существенно повысить эффективность производства, вместе с тем это может повлечь за собой не только ожидаемые положительные экстерналии, но и негативные, такие как сокращение рабочих мест или повышение экологической нагрузки на среду обитания. Согласно национальным целям устойчивого развития необходимо не только повысить внедрение инновационных разработок в реальный сектор экономики, но при этом обеспечить переход к рациональным моделям потребления и производства. Это говорит о том, что наряду с технологическими, организационными, маркетинговыми инновациями необходимо активнее внедрять экологические инновации. Несмотря на то, что внедрение инноваций позволяет существенно повысить конкурентоспособность организаций роста количества организаций, внедряющих инновации не наблюдается [1]. Напротив, за последнее десятилетие доля организаций, осуществляющих инновации снижается, особенно нисходящий тренд затронул экологические инновации (падение с 5,7\% в 2011 году до
0,6\% в 2018). Стоит отметить, что на принятие решения о реализации того или иного инновационного проекта влияет множество факторов, как внутренних, так и внешних, соответственно, на динамику организаций, внедряющих инновационные разработки, безусловно, повлияла сложная экономическая ситуация в России. Вместе с тем, повышение конкуренции в результате снижения платежеспособного спроса населения подталкивает организации осуществлять не только технологические инновации, но и инновации экологического характера.

Таким образом, рассмотрев количественные показатели внедрения инноваций в реальный сектор экономики, можно сделать вывод о том, что при существующем тренде внедрения инноваций повысить конкурентоспособность отечественных организаций и их продукции на мировом рынке будет достаточно проблематично. Исправить сложившуюся ситуацию может системный подход к поддержке организаций, внедряющих инновации со стороны государства, а также эффективное управление организацией при внедрении инновационных разработок. В связи с этим остро встает необходимость по методическому обеспечению организаций инструментами по эффективному управлению инновационными проектами.

Одним из способов повышения эффективности бизнес-процессов на предприятии является 


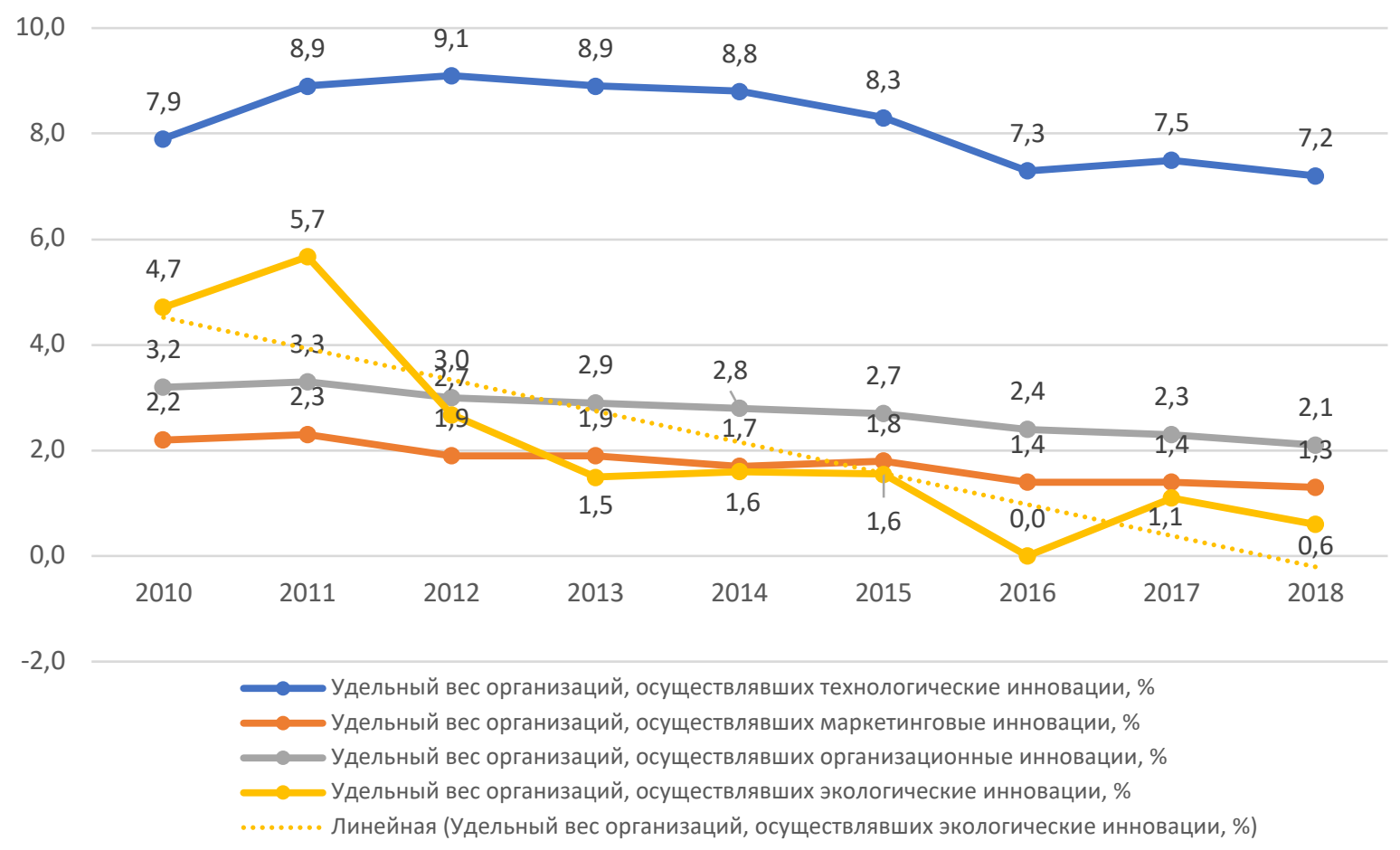

Puc. 1. Удельный вес организаций, осуществляющих инновации за период 2010-2018 годы, по видам инноваций [1]

* данные за 2016 год по экологическим инновациям не предоставлены

внедрение различных систем менеджмента на основе стандартов ISO серии 9000 и 14000. Однако, когда дело доходит до конкретного предприятия и применения стандартов для повышения эффективности и качества, обширное число вариантов выбора становится проблемой. Кроме того, вокруг применения стандартов ISO серии 14000 много споров. Несмотря на очевидные преимущества для компании, связанные с устойчивой положительной корреляцией между высокой экологической эффективностью, прибыльностью и общим благополучием, есть опасения со стороны высшего руководства, что достаточно затратный финансовый и ресурсный механизм, как на стадии внедрения, так и при функционировании, не даст нужного результата. Однако ужесточение экологического законодательства подталкивает компании к более внимательному отношению к окружающей среде, повышению безопасности производства и т.д., например, основными направлениями, обеспечивающие повышение экологической безопасности в процессе производства товаров, работ, услуг являются:

- Сокращение материальных затрат на производство единицы товаров, работ, услуг;

- Сокращение энергозатрат на производ- ство единицы товаров, работ, услуг;

- Сокращение выброса в атмосферу диоксида углерода (CO2);

- Замена сырья и материалов на безопасные или менее опасные:

- Снижение загрязнения окружающей среды (атмосферного воздуха, земельных, водных ресурсов, уменьшение уровня шума);

- Осуществление вторичной переработки (рециркуляции) отходов производства, воды или материалов;

- Сохранение и воспроизводство используемых сельским хозяйством природных ресурсов.

Таким образом, при реализации инновационных проектов на предприятии необходимо учитывать не только прибыль в кратко- и среднесрочной перспективе, но и учитывать экологические риски, поскольку возможное негативное воздействие на окружающую среду от реализации инновационного проекта может привести не только к финансовым потерям, но и имиджевым. Исходя из обозначенной проблематики необходимо рассмотреть существующие подходы к управлению инновационными проектами с учетом экологических рисков.

Разработка методических подходов реализации инновационных проектов в организации 
является актуальным как для отечественных ученых, так и для зарубежных. В связи с этим необходимо рассмотреть существующие методики управления экологическими инновационными проектами на предприятии.

Роговой А. А. предлагает авторскую классификацию эффектов от внедрения инновационного проекта:

- экономические;

- социальные;

- научно-технические;

- экологические.

При этом, эффект от внедрения инновационных проектов на микроуровне позволяет получить положительные эффекты как на мезо, так и на макроуровне. [15]

Павлова Е.И. рассматривает проблему оценки экологических инновационных проектов на уровне государства. [13] Автор предлагает вы- бирать наиболее перспективный экологический проект при помощи расчета показателя инновационного уровня проекта, который, в свою очередь рассчитывается путем совокупности трех компонент: х - экономическая компонента, у - экологическая компонента и z - социальная компонента (рис. 2).

Предложенный подход к оценке предполагает равнозначность результатов реализации инновационного проекта, что не позволяет говорить об универсальности предлагаемого подхода, вместе с тем, учитывается роль государства как основного заинтересованного лица в реализации экологических инноваций.

Авторы Какава Л.О и Лихачев Е.М. предлагают модель инновационного проектирования экологического инновационного проекта (рис. 3).

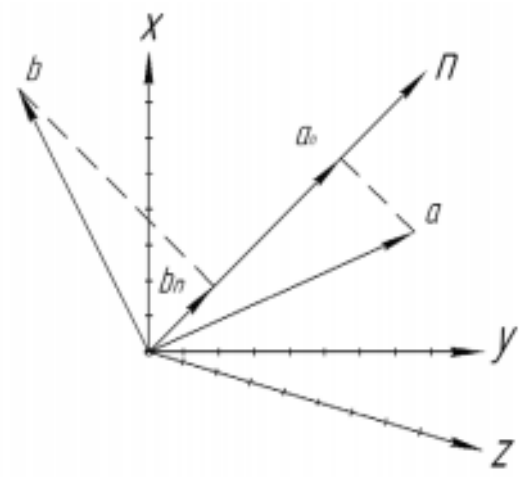

Puc. 2. Показатель инновационного уровня проекта [13]

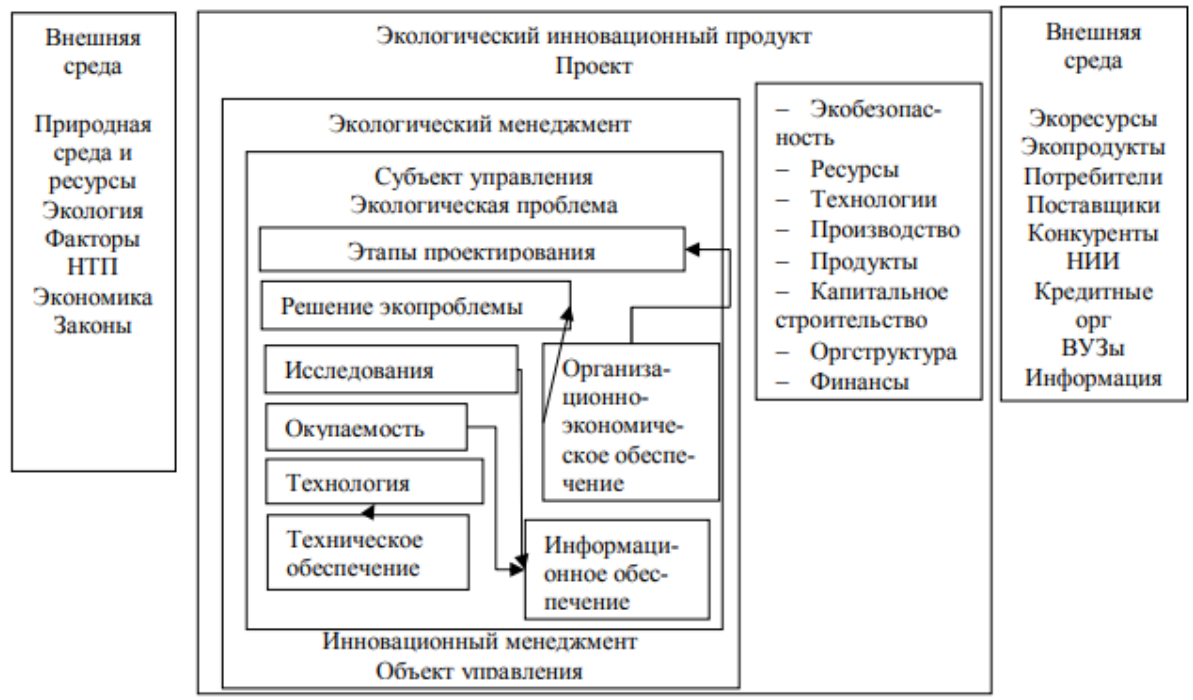

Puc. 3. Модель инновационного проектирования экологического инновационного проекта [8] 
Авторы выделяют среду, в которой реализуется экологический инновационный проект, которую они дифференцируют на внешнюю и внутреннюю. Во внешней среде основными факторами, воздействующими на проект, будут: экология, экономика, законодательные акты, научно-технический прогресс, потребители, поставщики, конкуренты, кредитные организации и информационная среда. К внутренним факторам авторы относят: финансы, технологические особенности производства, организационная структура, инвестиции в основной капитал и готовая продукция. Для успешной реализации экологического проекта авторы отмечают информационное и организационноэкономическое обеспечение проекта, а также технологии и техническое обеспечение. При этом решение экологической проблемы должно окупаться и приносить положительные эффекты для организации и способствовать достижению стратегических целей организации.

Наиболее интересным методом управления инновационными проектами может служить технология, разработанная А.В.Маслобоевым и В.В.Максимовой, [11] состоящая из пяти основных этапов, которая включает и основана на применении математического моделирования, а также позволяет проводить комплексный анализ и оценку эффективности экологических инноваций (рис 4).

Предложенный авторами метод обеспечивает возможность анализа эффективности как инновационных идей, так и детализированных инновационных проектов, включающих бизнес-план и примерную схему реализации основных этапов проекта. При этом авторы не учитывают экологические аспекты инновационных проектов на заключительных стадиях жизненного цикла инноваций, такие как утилизация и повторное использование.

Управление экологическими инновационными проектами на микроуровне активно изучают и зарубежные ученые, например, Graciela González и Raúl Mar. Они отмечают, что в условиях экономического и экологического кризиса компаниям необходимо внедрять инновационные проекты для повышения эффективности деятельности. Многие компании принимают политику управления окружающей средой, направленную на инновации, и поэтому стремятся к международному сотрудничеству для более быстрого развития бизнеса. Авторы исследовали возможность создания стратегии межфирменного взаимодействия, внедрения экологиче-

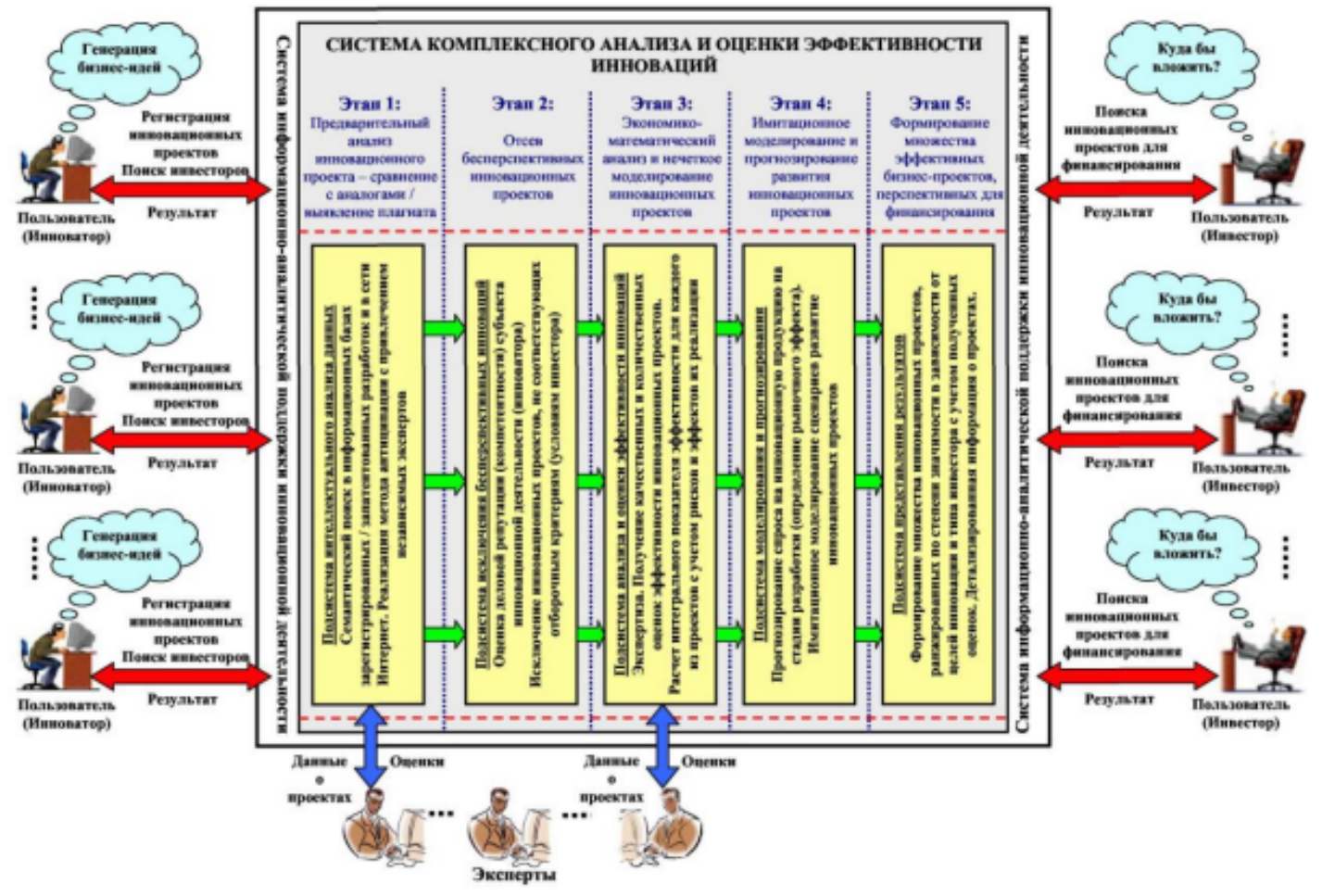

Puc. 4. Основные этапы функционирования системы комплексного анализа и оценки эффективности инноваций [11] 
ских инноваций для повышения эффективности деятельности организаций [1].

Коллектив авторов Renata Konadu, Samuel Owusu-Agyei, Theophilus Lartey и другие провели исследование взаимодействия репутации главного исполнительного директора и внедрения экологических инноваций, рассматривая управление качеством как посреднический механизм этих отношений. Более того, авторы выявили сдерживающую роль ресурсных обязательств во взаимосвязи между менеджментом качества и экологическими инновациями. В результате авторами было выявлено, что, когда фирма берет на себя обязательства по использованию ресурсов на методы управления качеством, повышается эффективность управления качеством в качестве одного из основных средств реализации экологических инноваций [2].

Наконец, коллектив авторов Львовско- го политехнического университета Mykola Odrekhivskyi, Uliana Kohut, Roman Kochan и другие разработали экологическую инновационную систему на основе инновационного процесса, которая направлена на ускорение разработки экологических инноваций и решение сложных вопросов глобальной экологической ситуации (рис. 5).

Практическая ценность работы заключается в том, что разработка глобальной экологической инновационной системы на разных уровнях (мега-, макро-, мезо- и микроуровень) иерархии будет способствовать быстрой разработке, распространению, внедрению и использованию экологической информации. Процесс экологических инноваций, лежащий в основе внедрения глобальной системы, позволит экологической сфере постоянно находиться в горизонтальном и вертикальном (национальном, международ-

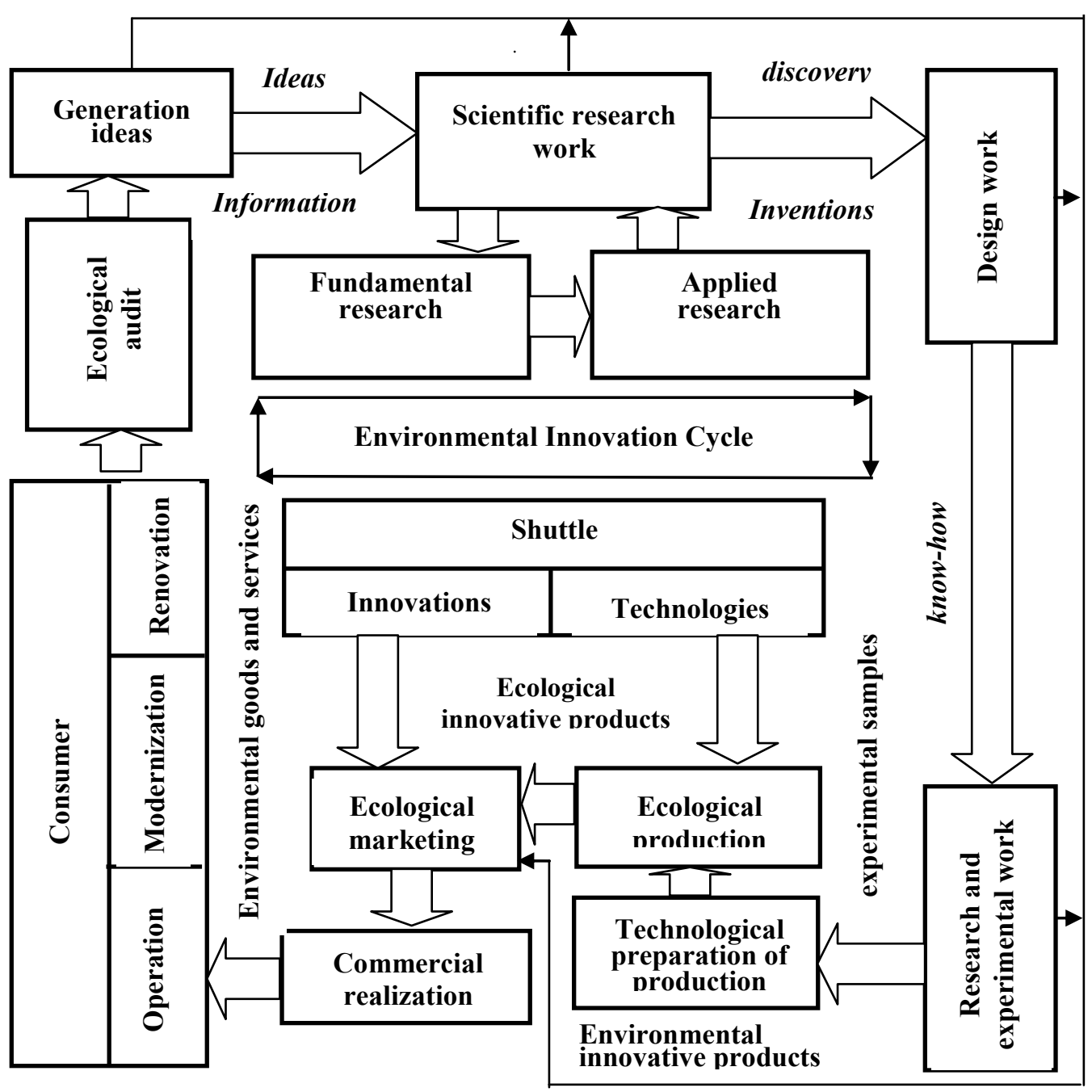

Puc. 5. Функциональная модель экологического инновационного процесса 
ном, глобальном) инновационных циклах. Все это поможет решить сложные экологические проблемы и улучшить глобальную экологическую ситуацию [5].

Таким образом, в результате проведения глубокого анализа существующих методик и подходов к управлению экологическими инновационными проектами, разработанных отечественными и зарубежными учеными, стоит отметить, что они не учитывают дифференциацию важности влияющих факторов на инновационный проект, при этом на микроуровне не отмечается управленческая деятельность на всем жизненном цикле по реализации проекта. Наконец, с точки зрения концепции постоянного улучшения не отмечается цикл Деминга, как одного из важных особенностей при разработке методики управления экологическими инновационными проектами. В связи с этим необходимо учесть выявленные особенности и предложить авторскую методику управления экологическими инновационными проектами.

Исходя из актуальности активизации внедрения экологических инновационных проектов на предприятиях, был проведен глубокий анализ отечественных и зарубежных методик и подходов к управлению экологическими инновационными проектами. Рассмотренные выше методики свидетельствуют о том, что тема является важной, а разработка, и совершенствование методического аппарата необходимы для повышения эффективности управления экологическими инновационными проектами. Вместе с тем, рассмотренные методики не учитывают дифференцию важности влияющих факторов на инновационный проект, при этом на микроуровне не отмечается управленческая деятельность на всем жизненном цикле по реализации проекта. В связи с этим, необходимо учесть выявленные особенности и предложить авторскую методику управления экологическими инновационными проектами.

Разработка методики позволит формализовать последовательность действий для субъектов управления на предприятии, чтобы выбрать наиболее результативные проекты, которые способствуют достижению стратегических целей предприятия. Разработка методики управления экологическими инновационными проектами состоит из четырех основных этапов (рис. 6).
На первом этапе определяются стратегические цели предприятия. В настоящее время на высококонкурентном рынке предприятиям невозможно развиваться без выстраивания долгосрочной стратегии развития. Поэтому крайне важно определить именно стратегические, долгосрочные цели на основе внешних и внутренних факторов, влияющих на деятельность организации. Исходя из стратегических целей организации можно сформулировать потребность в экологических инновационных проектах, реализация которых позволит добиться сформулированных целей организации.

Bторой этап заключается в формировании перечня экологических инновационных разработок, которые организация либо генерирует самостоятельно, либо занимается их поиском на рынке. Более подробно о генерации инновационных разработок было рассмотрено ранее [3, $4,9,10]$. При формировании перечня проектов необходимо учитывать перспективность разработки, ее потенциал внедрения на предприятии, влияние на окружающую среду и т.д.

После того, как будет сформирован перечень проектов необходимо провести оценку проектов по эффекту от их реализации на предприятии. Оценку необходимо проводить при помощи математических методов, например, при помощи нечетко-множественного подхода. Предложенный способ позволяет объективно проводить оценку инновационных проектов, формируя нечеткие интервалы оценки. Реализация экологических инновационных проектов позволяет получить четыре основных эффекта: экономический, научно-технический, социальный и экологический. Вместе с тем, необходимо отметить, что при реализации инновационных проектов организация может получить несколько эффектов $[7,11,14]$.

На третьем этапе производится отбор наиболее результативных проектов. Для осуществления отбора проектов необходимо рассчитать комплексный показатель эффекта от реализации экологического инновационного проекта. Комплексный показатель находим как сумму произведений эффектов от реализации и их весовых коэффициентов. При этом весовые коэффициенты можем расставить при помощи закона Фишберна. 


$$
\ni_{\kappa 1}=\sum \ni_{i} \times v_{j}
$$

где $Э_{\mathrm{i}}$ - эффекты от внедрения экологического инновационного проекта (экономический, научно-технический, социальный, экологический)

$\mathrm{v}$ - весовой коэффициент соответствующего эффекта.

В результате отбора получаем перечень наиболее результативных инновационных проектов для n-ой организации в n-ый промежуток времени.

На заключительном четвертом этапе формируется план реализации экологического инновационного проекта, который учитывает, как внутренние факторы организации, так и внешние. Основными внутренними факторами организации будут:

- ресурсы организации (финансовые, человеческие, интеллектуальные, технические, технологические, организационные);

- стандарты организации, внутренняя документированная база, обеспечивающая эффективную работу организации;

- системы менеджмента организации, например, соответствие стандартам серии ISO 9000 и 14000.

Совокупность внутренних факторов будет оказывать существенное влияние на план реализации экологического инновационного проекта, например, на срок реализации проекта ввиду организационной, технической, документированной и т.д. подготовки к реализации проекта.

Внешние факторы дифференцируем на две подгруппы: факторы, на которые организация не оказывает существенного влияния (политика государства, законодательная база, научнотехнический прогресс, экономическая ситуация в стране/регионе, экологическая ситуация в регионе) и факторы, на которые организация оказывает существенное влияние (потребители, конкуренты, заинтересованные лица).

В соответствии со сформированным планом реализации отобранных экологических инновационных проектов осуществляется внедрение проектов на предприятии [6, 12, 16, 17].

Таким образом, разработанная модель позволяет формализовать последовательность действий для субъектов управления на предприятии, чтобы выбрать наиболее результативные проекты, которые способствуют достижению стратегических целей предприятия, с учетом внешних и внутренних факторов.

Разработанная методика управления экологическими инновационными проектами требует более глубокой проработки методик формирования перечня экологических инновационных проектов, а также оценки эффекта от реализации проектов при помощи математического моделирования.

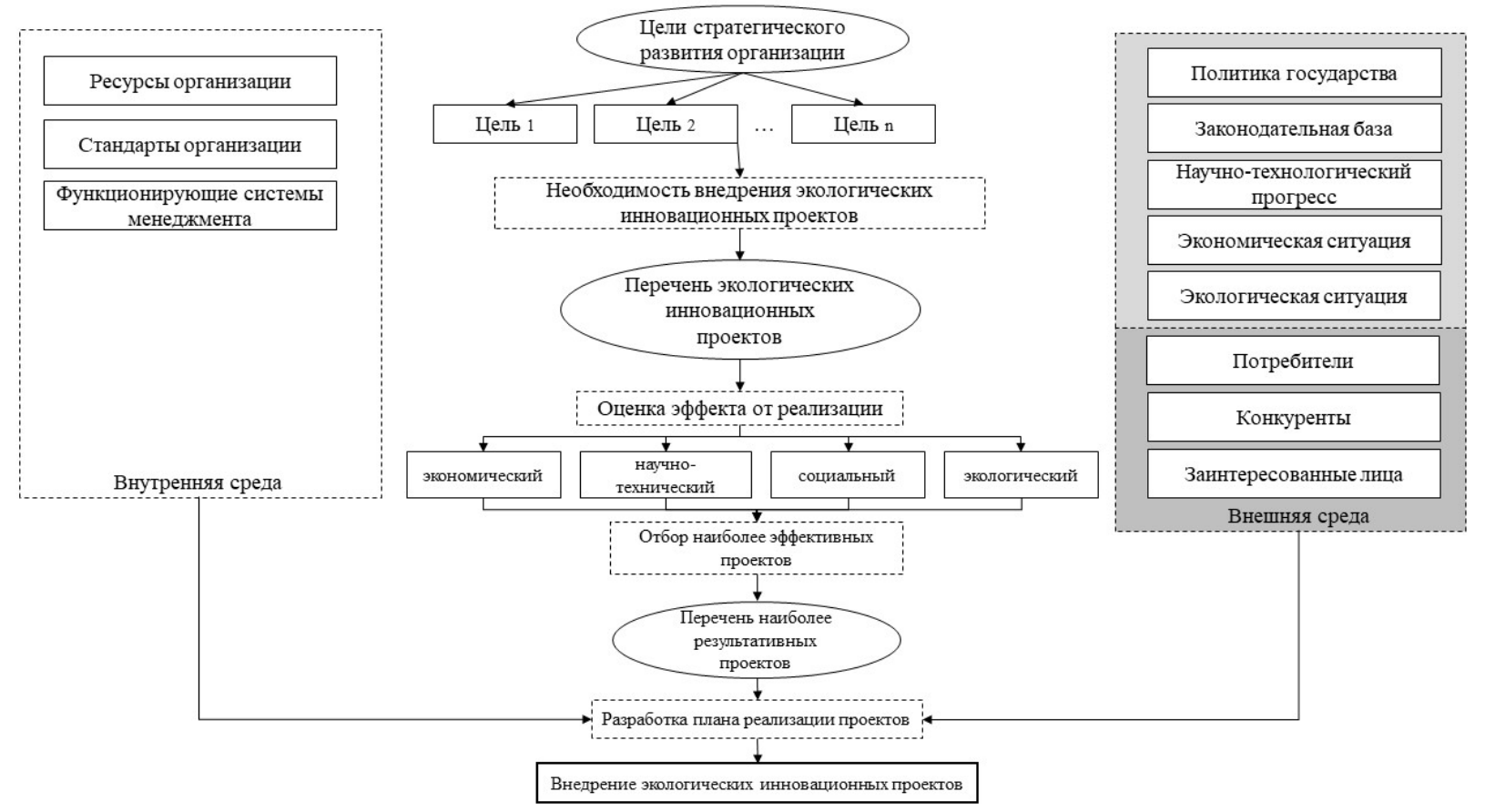

Рuc. 6. Концептуальная модель управления экологическими инновационными проектами на предприятии 
Перечень экологических инновационных проектов можно сформировать за счет внутреннего потенциала организации, т.е. разработать систему генерации инновационных проектов. Однако, большую часть инновационных разработок можно будет найти на рынке инновационных разработок. При этом, необходимо разработать методику отбора потенциально более эффективных инновационных проектов для организации.

Оценку эффекта от реализации инновационных проектов, как уже было предложено в исследовании, можно провести при помощи нечеткомножественного подхода.

Таким образом, было проведено глубокое исследование существующих методик и подходов к управлению экологическими инновационны- ми проектами, разработанных отечественными и зарубежными учеными. Они не учитывают дифференциацию важности влияющих факторов на инновационный проект, при этом на микроуровне не отмечается управленческая деятельность на всех этапах жизненного цикла по реализации проекта. Для того, чтобы аккумулировать существующие подходы и уточнить выявленные особенности была сформирована методика управления экологическими инновационными проектами. Методика позволяет формализовать последовательность действий для субъектов управления на предприятии, чтобы выбрать наиболее результативные проекты, которые способствуют достижению стратегических целей предприятия, с учетом внешних и внутренних факторов.

\section{Библиографический список}

1. González G. C., MarR.H. Inter-entrepreneurial management for environmental innovation. // Revue Sciences de Gestion. 2010. № 75.

2. Копаdи R. [и др.]. СЕОs' reputation, quality management and environmental innovation: The roles of stakeholder pressure and resource commitment // Business Strategy and the Environment. 2020. № 6 (29). C. 2310-2323.

3. Lуатіп В. [и др.]. Methodology of Intellectual Property Objects Commercial Potential Evaluation 2020.

4. Lyamin В. [и др.]. Stimulating innovative activities in the university 2020.

5. Odrekhivskyy М. [и др.]. Problems of environmental innovation systems design 2019.С. 587-594.

6. Абушова Е. Е. [и др.]. Разработка методики оценки уровня» бережливости» предприятия // Экономика и предпринимательство. 2020. № 8. С. 993-997.

7. Игольникова О. С., Копылов А. В. Нечетко-множественная модель оценки технической составляющей инновационного потенциала предприятия // Бизнес. Образование. Право. 2010. № 3. С. 124-131.

8. Какава Л. О., Лихачев Е. М. Модели инновационного проектирования в экологическом менеджменте // Научный журнал НИУ ИТМО. Серия «Экономика и экологический менеджмент». 2018. № 3.

9. Лямин Б.М., Моттаева А.Б. Роль инновационной деятельности высшего учебного заведения в достижении устойчивого развития // Управление социально-экономическим развитием регионов: проблемы и пути их решения. Материалы X Международной научно-практической конференции. 2020. (Курск).

10. Лямин Б.М., Моттаева А.Б. Оценка потенциала коммерциализации результатов инновационной деятельности в высшем учебном заведении // Экономические науки. 2020. (191). С. С. 81-88.

11. Маслобоев А. В., Максимова В.В. Метод и технология комплексной оценки эффективности инноваций на начальных этапах жизненного цикла на основе математического аппарата теории нечетких множеств // Труды Кольского научного центра РАН. 2010. № 3.

12. Никонова А. В., Широкова С. В. Совершенствование бизнес процессов медицинского учреждения и внедрение информационных технологий для повышения эффективности его деятельности 2019.С. 219-222.

13. Павлова Е.И. Экоинновации как фактор устойчивого развития экономики и оценка их уровня // Креативная экономика. 2014. № 2 (86).

14. Погребова О. А., Конников Е.А., Юлдашева О. У. Нечетко-множественная модель оценки индекса развития устойчивого маркетинга компании Федеральное государственное автономное образовательное учреждение высшего ..., 2017.С. 522-525.

15. Роговой А.А. Оценка эффективности симультантности разработки и коммерциализации биотехнологий в инновационном кластере // Вестник евразийской науки. 2015. № 1 (26) (7).

16. Соколова О. Н., Бутакова М. М. Организация инновационной деятельности на основе формирования и развития национальной и региональных инновационных систем // Вестник алтайской науки. 2015. № 3-4. С. 498-501.

17. Черникова А. В., Крылова Ю.И. Разработка системы критериев для оценки внедрения экологических стандартов на предприятиях 2019.С. 706-713. 